\title{
INSECTICIDAL AND FUNGICIDAL ACTIVITY OF A MAGNESIUM COMPOUND CONTAINING ISOVANILLIC ACID AGAINST LEAF-CUTTING ANT AND ITS SYMBIOTIC FUNGUS
}

\author{
Eldevan S. Silva ${ }^{a, b, c}$, Rafael C. Marchic, Carla Sthefane P. Matos ${ }^{\mathrm{b}}$, Maria Fátima G. F. Silva ${ }^{\mathrm{c}}$, João B. Fernandes ${ }^{\mathrm{c}}$, Odair C. \\ Bueno $^{\mathrm{d}}$ and Rose M. Carlos ${ }^{\mathrm{c}, *, \text { il }}$ \\ aDepartamento de Química, Centro Universitário UniFG, 46430-000 Guanambi - BA, Brasil \\ bDepartamento de Química, Universidade Estadual do Sudoeste da Bahia, 45208-091 Jéquie - BA, Brasil \\ 'Departamento de Química, Universidade Federal de São Carlos, 13565-905, São Carlos - SP, Brasil \\ ${ }^{\mathrm{d} I n s t i t u t o ~ d e ~ B i o c i e ̂ n c i a s, ~ U n i v e r s i d a d e ~ E s t a d u a l ~ P a u l i s t a, ~ 13506-900, ~ R i o ~ C l a r o ~-~ S P, ~ B r a s i l ~}$
}

Recebido em 07/09/2020; aceito em 09/11/2020; publicado na web em 15/12/2020

\begin{abstract}
Pesticides offer a simple, cost-effective solution to ensure food supplies for a growing world population. However, their environmental performance needs improvement if pesticides are to continue contributing importantly. This study explores the insecticidal potential of a magnesium (II) metal complex containing 1,10-phenanthroline and isovanillic acid (MgPhenIso) against leaf-cutting ant (Atta sexdens rubropilosa) and its symbiotic fungus (Leucoagaricus gongylophorus). The MgPhenIso complex is easy-to-prepare, stable in solid state and in aqueous solution, and resistant to sunlight irradiation. The insecticidal activity of MgPhenIso-containing bait against A. sexdens rubropilosa and L. gongylophorus showed a delayed action mode at $2 \mathrm{mg} \mathrm{g}^{-1}\left(100 \% \mathrm{kill} 6^{\text {th }}\right.$ day, $\left.\mathrm{S}_{50}=2 \mathrm{~b}\right)$ and suppressed fungus development and growth. These results, together with earlier investigations on MgPhenIso regarding its absence of toxicity to Zebrafish and Wistar male rats, emphasize the potential of this complex as an environmentally friendly insecticide candidate.
\end{abstract}

Keywords: pesticide; thermal and light resistance; natural product; agricultural microbiology; Atta sexdens rubropilosa.

\section{INTRODUCTION}

Sulfluramid, an N-ethylperfluorooctanesulfonamide, has been widely used as active principle in insecticidal baits for the control of leaf-cutting ants (Atta texana, Atta sexdens rubropilosa, Acromyrmex heyeri, tribe Attini, Hymenoptera Formicidae), ${ }^{1}$ in a large variety of crops susceptible to defoliation by these insects. ${ }^{2}$ In particular, the subspecies Atta sexdens rubropilosa is a pest of reforested and pasture areas. These ants infest regions of southern United States, Argentina and Brazil,${ }^{3}$ causing an annual loss of $17 \%$ of the cultivated area, ${ }^{4}$ with considerable economic damage.

Furthermore, leaf-cutting ants have a mutualistic relationship with its symbiotic fungus, Leucoagaricus gongylophorus. ${ }^{5}$ These ants produce antifungal bacteria to protect their symbiotic fungus from pathogenic fungi and pesticides. ${ }^{6}$ This close relationship has a significant influence on the development of pesticides.

Sulfluramid has been effectively used against leaf-cutting ants, eliminating $100 \%$ of ant colonies within a week. ${ }^{7}$ It is a delayed action toxicant that allows ants to collect large amounts of the bait before dying, and it works by interfering with the cell respiration process via the uncoupling of oxidative phosphorylation. ${ }^{8}$ However, there are serious restrictions to the use of this insecticide. ${ }^{9}$ Sulfluramid is a perfluorinated compound that is degraded to perfluoroctyl sulfonate (PFOS). Considering the environmental hazards and risks of PFOS, all pesticide products based on the release of this acid have been banned or restricted in many countries since $2000{ }^{10,11}$ Unfortunately, due to lack of safer alternatives with a reasonable cost, sulfluramid continues to be produced and used for agricultural purposes in many other countries. ${ }^{12}$

Approximately two decades ago, natural products extracted from different plants were described to present protective effects on the defense system of plants against pathogens and environmental stresses..$^{13}$ Due to these characteristic, plant extracts have attracted much attention because of the employment of polyphenolic

*e-mail: rosem@ufscar.br compounds in diverse areas of science, such as insecticide and fungicide production. ${ }^{14,15}$ Coordination of polyphenolic compounds to the metal centers has also been currently used to improve and enhance the scope of biological applications of these complexes. Polyphenolic compounds are good electron donors and, therefore, stable chelate complexes are expected and indeed formed with a great variety of metal ions, including those with $\mathrm{Sn}(\mathrm{II}), \mathrm{Cu}(\mathrm{II}), \mathrm{Zn}(\mathrm{II}), \mathrm{Ru}(\mathrm{II})$ and $\mathrm{Mg}(\mathrm{II}) .{ }^{16-19}$ Moreover, metal complexes with chelate ligands offer the high stability needed for applications where chemical bonds have to remain intact, as in pesticides.

These findings encouraged us to prepare the complex MgPhenIso, where phen is 1,10-phenanthroline and Iso is isovanillic acid, Figure 1S. The MgPhenIso complex was designed to potentiate synergistic action between magnesium (II) and the phenolate group of the isovanillic acid ligand.

Magnesium is interesting for use in agricultural applications because of its abundance, low cost, and protective effects on plants. ${ }^{20}$ Magnesium is the seventh most abundant element in the Earth's crust and the second in human cells. ${ }^{21}$ It plays an important role in human health, assisting with aging and many diseases such as depression and stress, which require increased magnesium absorption. ${ }^{21}$ Magnesium intake recommendation is $200-400 \mathrm{mg} / \mathrm{day} .{ }^{22}$ For plants, magnesium is essential for growth and development, such that $\mathrm{Mg}$ supply on Mg-deficient sites increase the quality of agricultural crops. ${ }^{23}$ More recently, the role played by $\mathrm{Mg}$ in the stress physiology of plants has been demonstrated. ${ }^{23}$

Recent studies conducted in our laboratory have demonstrated that the easy-to-synthesize, water soluble MgPhenIso complex presents properties that emphasize the potential of this complex as an environmentally safe compound. ${ }^{24}$ This study shows the presence of two structures in solution, Figure 1S, the hexa- and tetra-coordinated complexes, here described as MgPhenIso complex. Also, shows that the MgPhenIso complex presents antioxidant activity in vitro and probably in vivo, is not toxic and does not cause mortality or visual alterations to Zebrafish exposed to it at concentrations up to $2.0 \mathrm{mg} \mathrm{L}^{-1}$ 
after $96 \mathrm{~h}$ and to Wistar male rats exposed to a $3.0 \mathrm{mg} \mathrm{kg}^{-1}$ day $^{-1}$ dose for 21 days. The MgPhenIso complex did not affect the activity of brain-acethylcholinesterase, digestive-tract-catalase and glutathioneS-transferase enzymes of both fish and rat. Conversely, performance of superoxide dismutase activity increased in the presence of complex, resulting in enhanced capacity of both animal species for superoxide radical enzymatic scavenging. ${ }^{24}$

The present study extends our previous investigation on the insecticidal properties of MgPhenIso against leaf-cutting ants (Atta sexdens rubropillosa), through oral ingestion assays, and its symbiotic fungus (Leucoagaricus gongylophorus), via proliferation in culture medium.

The results indicate an interesting profile of biological activity with strong insecticidal activity against both the leaf-cutting ant and its symbiotic fungus. Additionally, $\mathrm{MgPhenI}$ so shows high stability in solid state and in aqueous medium in the dark and when exposed to sun light. These features, together with its low lipophilicity, suggest that MgPhenIso will present low persistence in aquatic medium and will probably be degraded by microbial processes.

\section{EXPERIMENTAL}

\section{Synthesis of the MgPhenIso complex}

The MgPhenIso complex was synthesized by the reaction of isovanilic acid, 1,10-phenathroline, and $\mathrm{Mg}\left(\mathrm{CH}_{3} \mathrm{COO}\right)_{2} \cdot 4 \mathrm{H}_{2} \mathrm{O}$ in methanol using a procedure in literature ${ }^{24}$ and described at the Supplementary Material.

\section{Determination of solubility}

Solubility of the complex in phosphate buffer solution $(\mathrm{pH}=7.40)$ was determined at $37.0 \pm 0.5{ }^{\circ} \mathrm{C}$ by the shake-flask method. ${ }^{25} \mathrm{~A}$ saturated solution of MgPhenIso was prepared in $2 \mathrm{~mL}$ of buffer solution and stirred for $24 \mathrm{~h}$ at $50 \mathrm{rpm}$ until equilibrium. Then, the sample was centrifuged for 5 minutes and the concentration of the filtered complex was determined using the UV-Vis spectrophotometer.

\section{Potentiometric pKa determination of the complex}

The pKa determinations were performed in triplicate following the procedure described by Reijenga and Hoof. ${ }^{26} 6.0 \mathrm{mg}$ of MgPhenIso was solubilized in $15.0 \mathrm{~mL}$ of milli-Q water and the $\mathrm{pH}$ was adjusted to 12 with a $\mathrm{NaOH}$ solution. Aliquots of $250 \mu \mathrm{L}$ of standard $\mathrm{HCl}$ solution were added to the sample, and the $\mathrm{pH}$ was recorded obtaining a titration curve $(\mathrm{pH} \times \mathrm{V}(\mathrm{mL})$ of $\mathrm{HCl})$.

\section{Stability of study in ${ }^{1} \mathrm{H}$ NMR}

$4.0 \mathrm{mg}$ of the complex were added to $600 \mu \mathrm{L}$ of buffer solution in deuterated water $\left(\mathrm{D}_{2} \mathrm{O}\right)(\mathrm{pH}=7.4)$, and stability was investigated by ${ }^{1} \mathrm{H}$ NMR every $12 \mathrm{~h}$ for $120 \mathrm{~h}$. Two groups of samples were prepared: after the first reading at $\mathrm{t}=0 \mathrm{~h}$, one group of samples was protected from light and the other group was exposed to sunlight throughout the experiment.

\section{Leaf-cutting ant insecticidal bioassay}

The methods used for the insecticidal bioassay have been previously described in the literature. ${ }^{27,28}$ Bioassays were performed against the ant species Atta sexdens rubropilosa. Worker ants with body mass of 20.0-25.0 mg were randomly collected from laboratory nests. Prior to the assays, the nests were supplied daily with Eucalyptus sp. leaves, oat seeds and, occasionally, with leaves of other plants such as Hibiscus sp. and Ligustrum sp. or rose petals. Ten ants were used per treatment, with 5 repetitions $(n=50)$. During the assays, the ants were maintained under artificial diet prepared with glucose $\left(50.0 \mathrm{~g} \mathrm{~L}^{-1}\right)$, bacto-peptone $\left(10.0 \mathrm{~g} \mathrm{~L}^{-1}\right)$, yeast extract (1.0 $\left.\mathrm{g} \mathrm{L}^{-1}\right)$, and agar $\left(15.0 \mathrm{~g} \mathrm{~L}^{-1}\right)$ in distilled water $(25.0 \mathrm{~mL})$. The diet (0.40-0.50 g per dish) with (experiment) or without (control) addition of the test compounds was offered daily in small plastic caps. The positive control group included ants exposed to sulfluramid at a potentially toxic concentration, whereas the negative control (NC) group comprise ants receiving the control diet alone.

The compounds (MgPhenIso and sulfluramid) were poured into the hot diet immediately after it was autoclaved. The final concentrations of the compounds added to the diet were $0.2 \mathrm{mg} \mathrm{mL}^{-1}$, $1.0 \mathrm{mg} \mathrm{mL}^{-1}$ and $2.0 \mathrm{mg} \mathrm{mL}^{-1}$, respectively. These three different concentrations corresponded to each treatment with 10 ants. During the assays, the Petri dishes with all the treatments were maintained in an incubator at $25 \pm 1{ }^{\circ} \mathrm{C}$ and $70-80 \%$ relative humidity. The Petri dishes were examined daily for 25 days, which corresponds to the lifetime of this ant species under normal laboratory conditions, and dead ants were removed. Data were recorded daily. For the survival analyses, the data were submitted to a non-parametric analysis to compare the survival curves using the Logrank test in the Graph$\mathrm{Pad}^{\mathrm{TM}}$ Prisma software. Bioassays were conducted in duplicate or five-fold and expressed as mean $\pm \mathrm{SD}$. One-way analyses of variance (ANOVA) was performed, and significant differences between the means were determined by the Duncan's multiple range test. All tests were regarded as statistically significant when $p<0.05$.

\section{Fungicidal bioassays}

The fungus Leucoagaricus gongylophorus was isolated from a laboratory nest of Atta sexdens rubropilosa ants. The medium for fungus maintenance and methods for the bioassays have been previously described in the literature..$^{27,28}$ The experiments with the symbiotic fungus L. gongylophorus were conducted in the Laboratory of Natural Product Bioassays at the Federal University of São Carlos (UFSCar). The fungus Leucoagaricus gongylophorus (Möller) Singer was isolated from an A. sexdens rubropilosa laboratory nest and maintained in laboratory in culture medium composed of malt extract $\left(20 \mathrm{~g} \mathrm{~L}^{-1}\right)$, bacto-peptone $\left(5 \mathrm{~g} \mathrm{~L}^{-1}\right)$, yeast extract $\left(2 \mathrm{~g} \mathrm{~L}^{-1}\right)$, and agar $\left(20 \mathrm{~g} \mathrm{~L}^{-1}\right)$. For the assay, methanol was used as control and free isovanillic acid and magnesium acetate at a concentration of $100 \mathrm{mg} \mathrm{L}^{-1}$ were used for the MgPhenIso complex. The samples submitted to the assay with the symbiotic fungus were previously dissolved in $500 \mu \mathrm{L}$ methanol and incorporated into the culture medium with subsequent addition of distilled water. Subsequently, $10 \mathrm{~mL}$ of culture medium with or without the incorporated sample were added to each tube. After sterilization of the material, culture medium was poured into the Petri dishes $(80 \times 15 \mathrm{~mm})$ inside a laminar flow cabinet previously sterilized for $30 \mathrm{~min}$ using ultraviolet light. After solidification of the culture medium, each Petri dish was inoculated with a disc agar $(8 \mathrm{~mm})$ previously colonized by the symbiotic fungus $L$. gongylophorus in the center position. After the incubation at $25{ }^{\circ} \mathrm{C}$ for 30 days, inhibition calculations were performed in the areas of mycelia growth of the symbiotic fungus in each sample. The assays were run in five-fold.

\section{RESULTS AND DISCUSSION}

\section{Synthesis and characterization of MgPhenIso}

The MgPhenIso complex was synthesized by the reaction of isovanillic acid, 1,10-phenanthroline, and $\mathrm{Mg}\left(\mathrm{CH}_{3} \mathrm{COOH}\right)_{2} \cdot 4 \mathrm{H}_{2} \mathrm{O}$ in 


\section{Exposure to sun light}

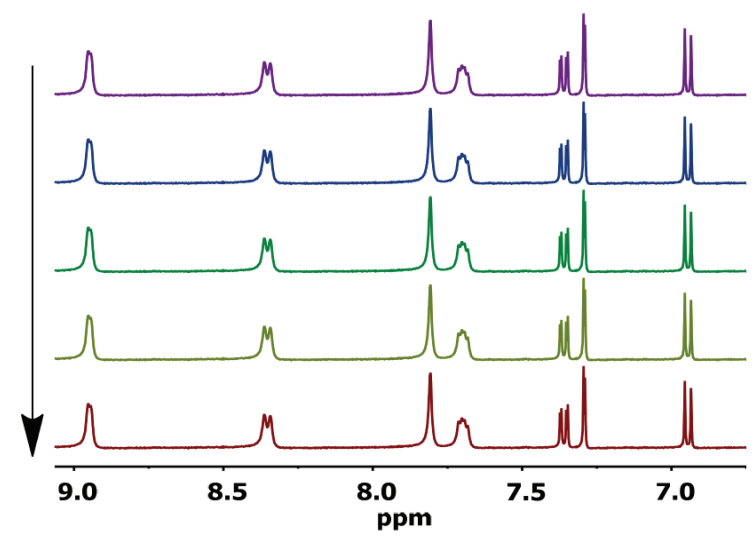

Kept in the dark

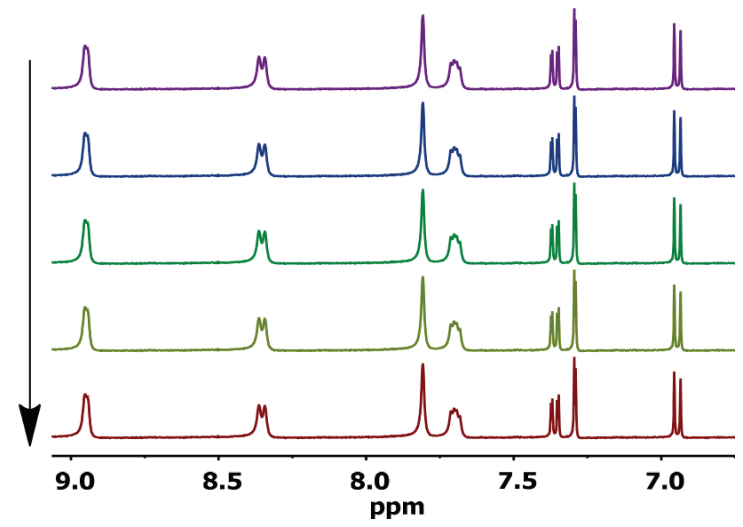

Figure 1. ${ }^{1} \mathrm{H}-\mathrm{NMR}$ of MgPhenIso in buffer solution at pH 7.4 monitored as a function of time: 0 (violet), 24 (blue), 48 (green), 72 (olive) and 120 (brown) $\mathrm{h}$

methanol using the procedure previously established. ${ }^{24}$ The complex was characterized by ESI-mass spectrometry and NMR, Figures $2 \mathrm{~S}$ and $3 \mathrm{~S}$.

\section{Physicochemical properties}

A potential pesticide candidate should present stability in the dark and under extended natural sunlight exposure and water solubility properties to avoid deleterious environmental impact. ${ }^{29,30}$ The MgPhenIso complex is stable in solid state and in aqueous solution both in the dark and under natural sunlight exposure. The chemical stability was proved by the absence of changes in the ${ }^{1} \mathrm{H}$ NMR spectra in $\mathrm{D}_{2} \mathrm{O}(\mathrm{pH}=7.4)$ for at least $120 \mathrm{~h}$ of MgPhenIso exposure to natural sunlight and in the dark (protected from light), Figure 1. These results indicate the high resistance of $\mathrm{MgPhenIso}$ to photodegradation.

The $\mathrm{pKa}$ value obtained for the MgPhenIso complex was 6.11, Figure 2, which corresponds to the phenol moiety since the acid part is being used as chelate. Two values were observed for the free isovanillic acid, 4.08 and $8.54,{ }^{31}$ corresponding to the carboxylic acid moiety and the phenol moiety, respectively. When the complex is formed, there is a reduction in the pKa value from the free ligand, indicating that the proton is easily donated within the complex. This fact was previously detected using cyclic voltammetry, which showed a difference in the oxidative potential between the free isovanllic acid and the MgPhenIso complex. ${ }^{24}$

A systematic knowledge on the solubility of the potential pesticide is important to the agroindustry, since highly soluble pesticides can contaminate ground water and cause damage to the

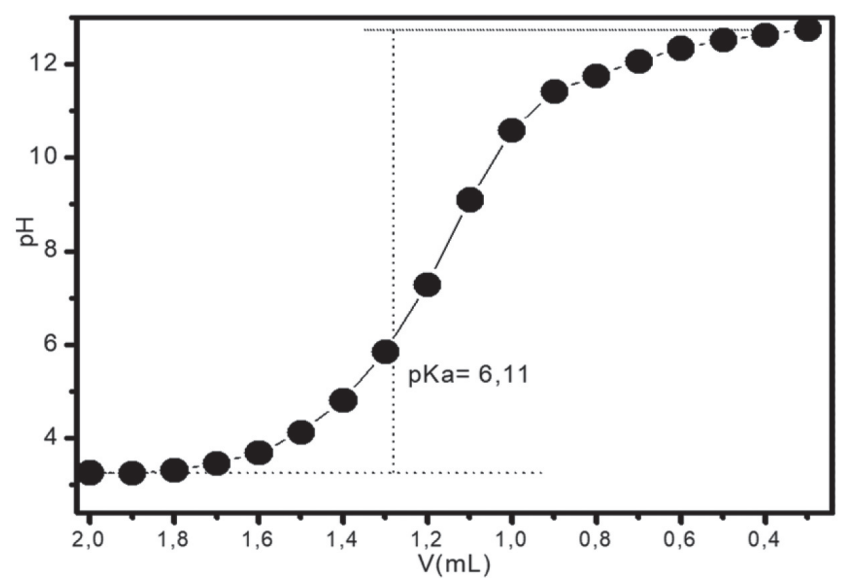

Figure 2. Potentiometric titration curve for MgPhenIso aquatic environment. ${ }^{32}$ The solubility of the MgPhenIso complex is much higher $\left(314.13 \pm 2.13 \mu \mathrm{g} \mathrm{mL}^{-1}\right)$ than that of the free isovanillic acid $\left(80.12 \pm 1.49 \mu \mathrm{g} \mathrm{mL}^{-1}\right)$ in aqueous solution $(\mathrm{pH} 7.4)$ at $25^{\circ} \mathrm{C}$ (298 K). In general, PFOS have solubility around $550 \mu \mathrm{g} \mathrm{mL}^{-1}$, which is higher than that of the complex. ${ }^{33}$ Based on this higher solubility, toxicity, and difficulty in rapid detection (for example, using UV-vis) associated with PFOS, the MgPhenIso complex has the advantage of being as soluble as PFOS, but less toxic and more easily detected using non-expensive techniques in case leak occurs.

\section{Insecticidal activity against Atta sexdens rubropilosa and its symbiotic fungus Leucoagaricus gongylophorus}

Table 1 shows the time-dependent toxicity data of leaf cutting worker ants (Atta sexdens rubropilosa) treated and fed on artificial diet (negative control group), sulfluramid (positive control group), free isovanillic acid, and MgPhenIso. The survival rates of the ants did not differ significantly between the negative control group and the group treated with free isovanillic acid. In contrast, the MgPhenIso group showed a markedly dose-dependent toxicity comparable to that of the commercial pesticide Sulfluramid, although it presented a delayed action mode and caused mortality faster than Sulfluramid $\left(0.2 \mathrm{mg} \mathrm{g}^{-1}, \mathrm{~S}_{50}=5 \mathrm{~b}\right.$ in 10 days $)$.

The studies were also extended to evaluate the effects of $\mathrm{MgPhenIso}$ and free isovanillic acid on the Leucoagaricus gongylophorus fungus. Table 2 shows the mean colony diameters in centimeters and the percentage inhibition of fungal development after 30 days of experiment. As shown in Figure 3, at $100 \mathrm{mg} \mathrm{L}^{-1}$, MgPhenIso suppressed all fungal growth.

Although many plant-derived pesticides have shown strong deleterious effects on leaf-cutting ants and/or their symbiotic fungus with no environmental toxicity, only a few of them are currently available on the market. Among them the botanical insecticides Ryania speciosa (Ryanodine) and Tanacetum cinerariaefolium (pyrethrins) and the extracts of Azadirachta indica (neem), Rosmarinus officinale (Rosemary oil; 1,8-Cineole) and Syzygium aromaticum (clove oil, Eugenol) are the most effective. ${ }^{34}$ For instance, neem oil extract was toxic at concentrations up to $5 \mathrm{mg} / \mathrm{mL}\left(\mathrm{S}_{50}=0.67\right) .^{35,36}$

Low solubility in aqueous solution and instability when exposed to sun light are limiting factors to neem oil extract and other insecticides. Additionally, many studies have demonstrated the toxic effects of neem oil extract/commercial formulations on aquatic organisms and on non-target predators/pest. Studies have reported decreased general activity and increased anxiety-like behavior following exposure of Zebrafish to 20 or $40 \mu \mathrm{L} / \mathrm{L}$ of neem extract. ${ }^{36-38}$ 
Table 1. Mortality $(\%)$ and survival median 50\% $\left(\mathrm{S}_{50}\right)$ of Atta sexdens rubropilosa workers fed on artificial diet with free isovanillic acid, MgPhenIso, and Sulfluramid

\begin{tabular}{|c|c|c|c|c|c|c|c|c|c|c|c|}
\hline \multirow{2}{*}{ Treatment } & \multicolumn{11}{|c|}{$\%$ Daily accumulated mortality } \\
\hline & 1 & 2 & 3 & 6 & 8 & 10 & 14 & 17 & 21 & 25 & $\mathrm{~S}_{50} *$ \\
\hline Control diet & 0 & 4 & 4 & 6 & 6 & 8 & 12 & 14 & 22 & 28 & $>25 a$ \\
\hline Free isovanillic acid & 0 & 0 & 6 & 12 & 18 & 24 & 28 & 32 & 40 & 44 & $>25 a$ \\
\hline MgPhenIso $\left(0.20 \mathrm{mg} \mathrm{g}^{-1}\right)$ & 0 & 2 & 4 & 14 & 18 & 28 & 58 & 76 & 90 & 94 & $13 b$ \\
\hline MgPhenIso (1.0 $\left.\mathrm{mg} \mathrm{g}^{-1}\right)$ & 6 & 22 & 56 & 90 & 98 & 100 & 100 & 100 & 100 & 100 & $3 b$ \\
\hline MgPhenIso (2.0 $\left.\mathrm{mg} \mathrm{g}^{-1}\right)$ & 4 & 48 & 78 & 100 & 100 & 100 & 100 & 100 & 100 & 100 & $2 b$ \\
\hline Sulfluramid $\left(0.20 \mathrm{mg} \mathrm{g}^{-1}\right)$ & 0 & 8 & 20 & 70 & 98 & 100 & 100 & 100 & 100 & 100 & $5 b$ \\
\hline
\end{tabular}

*Different letters after $\mathrm{S}_{50}$ values show significant difference according to the Logrank test $(p<0.05)$.

Table 2. Inhibitory effects on fungal growth by free isovanillic acid, magnesium acetate, and MgPhenIso

\begin{tabular}{lcc}
\hline Treatment & Colony diameter $(\mathrm{cm})$ & \% inhibition \\
\hline Control & $8.20 \pm 1.08$ & 0 \\
Isovanillic acid & $4.90 \pm 0.19$ & 40 \\
Magnesium acetate & $7.45 \pm 0.17$ & 9 \\
MgPhenIso & 0 & 100 \\
\hline
\end{tabular}
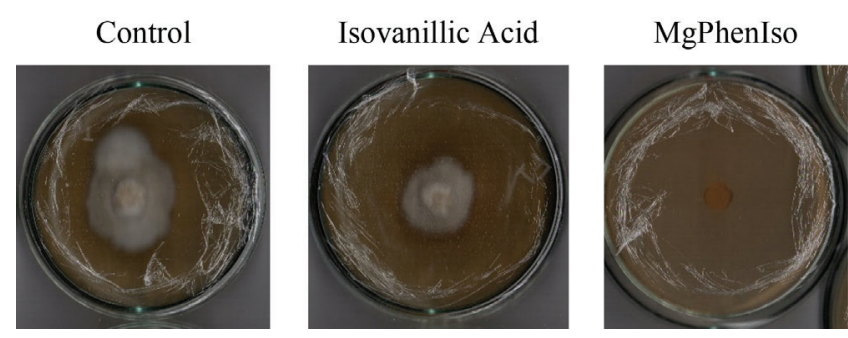

Figure 3. The image shows the mycelial growth of Leucoagaricus gongylophorus fungus after 30 days of incubation with $500 \mu \mathrm{L}$ of methanol as control, isovanillic acid and MgPhenIso

The combination of delayed toxicity that suppresses populations of leaf-cutting ants together with the ability to exterminate the ant colony after 30 days of treatment are a clear evidence of the insecticidal potential of the MgPhenIso complex. When compared with the previously mentioned insecticides, MgPhenIso exhibited both high insecticidal and fungicidal activities that increase the control efficacy, no apparent toxicity to aquatic and territorial organisms, and anxiolytic effects on live beings. ${ }^{24}$ These results evidence the insecticidal potential of the MgPhenIso complex.

\section{CONCLUSIONS}

The results indicate an interesting profile of biological activity with strong insecticidal activity against both leaf-cutting ant (Atta sexdens rubropilosa) and its symbiotic fungus (Leucoagaricus gongylophorus). The high stability in solid state and in aqueous medium in the dark and when exposed to sun light and the low lipophilicity suggest that the MgPhenIso complex will have low persistence in aquatic medium. These results, together with the lack of toxicity for Zebrafish and Wistar male rats reported in a previous publication, emphasize the potential of MgPhenIso as an environmentally friendly insecticide.

\section{SUPPLEMENTARY INFORMATION}

Synthesis and characterization (ESI-MS and ${ }^{1} \mathrm{H}-\mathrm{NMR}$ ) of the complex is described at the supplementary material and free of charge at http://quimicanova.sbq.org.br.

\section{ACKNOWLEDGEMENTS}

This work was supported by the São Paulo Research Foundation (FAPESP) under Grants numbers 2013/05536-6, 2015/231466, 2017/00839-1, 2017/15455-4, 2018/09145-5, 2018/16040-5, 2019/21143-0; National Council for Scientific and Technological Development (CNPq) under Grants numbers 455630/2014-3, 166303/2017-8, 306005/2017-4; and Coordination of Superior Level Staff Improvement (CAPES) under finance code 001.

\section{REFERENCES}

1. Forti, L. C.; Pretto, D. R.; Nagamoto, N. S.; Padovani, C. R.; Camargo, R. S.; Andrade, A. P. P.; Sociobiology 2007, 50, 1149.

2. Canuto, D. M. F.; dos Reis, S. F.; Godoy, W. A. C.; Open Journal of Statistics 2019, 9, 196.

3. Della Lucia, T. M.; Gandra, L. C.; Guedes, R. N.; Pest Manage. Sci. 2014, 70, 14.

4. Catalani, G. C.; Sousa, K. K.; da Camargo, R. S.; Caldato, N.; Matos, C. A.; Forti, L. C.; Rev. Bras. Entomol. 2019, 63, 290.

5. Blatrix, R.; Djiéto-Lordon, C.; Mondolot, L.; La Fisca, P.; Voglmayr, H.; McKey, D.; P. Proc. R. Soc. B 2012, 3940.

6. Samuels, R. I.; Mattoso, T. C.; Moreira, D. D.; Communicative \& Integrative Biology 2013, 6, e23095.

7. Zanuncio, J. C.; Mourão, S. A.; Martínez, L. C.; Wilcken, C. F.; Ramalho, F. S.; Plata-Rueda, A.; Soares, M. A.; Serrão, J. E.; Sci. Rep. 2016, 6,1 .

8. De Britto, J. S.; Forti, L. C.; de Oliveira, M. A.; Zanetti, R.; Wilcken, C. F.; Zanuncio, J. C.; da Silva Camargo, R.; Int. J. Res. Environ. Stud. 2016, 3,11

9. IPEN-Toxic Free, 2019, Say no to sulfluramid: reasons for a worldwide ban on this agrotoxic chemical, available at https://ipen.org/sites/default/ files/documents/en_ipen-sulfuramide -factsheet-v1_10a-en.pdf, accessed December 2020.

10. Renner, R.; Environ. Sci. Technol. 2008, 42, 4618.

11. All POPs listed in the Stockholm Convention, available at http://chm. pops.int/TheConvention/ThePOPs/AllPOPs/tabid/2509/Default.aspx, accessed December 2020.

12. Nascimento, R. A.; Nunoo, D. B.; Bizkarguenaga, E.; Schultes, L.; Zabaleta, I.; Benskin, J. P.; Spanó, S.; Leonel, J.; Environ. Pollut. 2018, 242, 1436.

13. Yang, L.; Wen, K. S.; Ruan, X.; Zhao, Y. X.; Wei, F.; Wang, Q.; Molecules 2018, 23, 762 .

14. Amoabeng, B. W.; Johnson, A. C.; Gurr, G. M.; Appl. Entomol. Zool. 2019, $54,1$. 
15. Isman, M. B.; Ann. Rev. Entomol. 2020, 65, 233.

16. Dehghan, G.; Khoshkam, Z.; Food Chem. 2012, 131, 422.

17. Oliveira, R. M.; de Souza Daniel, J. F.; de Aguiar, I.; Silva, M. F. D. G. F.; Fernandes, J. B.; Carlos, R. M.; J. Inorg. Biochem. 2013, 129, 35.

18. Mendiguchia, B. S.; Aiello, I.; Crispini, A.; Dalton Trans. 2015, 44, 9321.

19. Khater, M.; Ravishankar, D.; Greco, F.; Osborn, H. M.; Future Med. Chem. 2019, 11, 2845.

20. Guo, W.; Nazim, H.; Liang, Z.; Yang, D.; The Crop Journal 2016, 4, 83.

21. De Baaij, J. H.; Hoenderop, J. G.; Bindels, R. J.; Physiol. Rev. 2015, 95, 1.

22. Nielsen, F. H.; Biol. Trace Elem. Res. 2019, 188, 52.

23. Senbayram, M.; Gransee, A.; Wahle, V.; Thiel, H.; Crop Pasture Sci. 2016, 66, 1219.

24. Marchi, R. C.; Silva, E. S.; Santos, J. J.; Guiloski, I. C.; de Jesus, H. C. R.; de Aguiar, I.; Kock, F. V.C.; Venâncio, T.; da Silva, M. F. G. F.; Fernandes, J. B.; Vital, M. A. B. F.; Souza, L. C. S.; de Assis, H. C. S.; Skibsted, L. H.; Carlos, R. M.; ACS Omega 2020, 5, 3504

25. Baka, E.; Comer, J. E.; Takács-Novák, K.; J. Pharma. Biomed. 2008, 46, 335.

26. Reijenga, J. van Hoof, A.; van Loon, A.; Teunissen, B.; Anal. Chem. Insights 2013, 8, ACI-S12304.

27. Miyashira, C. H.; Tanigushi, D. G.; Gugliotta, A. M.; Santos, D. Y. A. C. D.; Braz. J. Microbiol. 2010, 41, 506
28. Bicalho, K. U.; Terezan, A. P.; Martins, D. C.; Freitas, T. G.; Fernandes, J. B.; Da Silva, M. F. D. G.; Vieira, P. C.; Pagnocca, F. C.; Bueno, O. C.; Psyche: A Journal of Entomology 2012, 2012.

29. Akamatsu, M.; J. Agric. Food Chem. 2011, 2909.

30. Rao, H.; Huangfu, C.; Wang, Y.; Wang, X.; Tang, T.; Zeng, X.; Li, Z; Chen, Y.; Mol. Inf. 2015, 34, 331.

31. Erdemgil, F. Z. Şanli, S.; Şanli, N.; Özkan, G.; Barbosa, J.; Guiteras, J.; Beltran, J. L.; Talanta 2007, 72, 489.

32. Kulkarni, A. R.; Soppimath, K. S.; Dave, A. M.; Mehta, M. H.; Aminabhavi, T. M.; J. Hazard. Mater. 2000, 80, 9.

33. Zabaleta, I.; Bizkarguenaga, E.; Nunoo, D. B.; Schultes, L.; Leonel, J.; Prieto, A.; Zuloaga, O.; Benskin, J. P.; Environ. Sci. Technol. 2018, 52, 2603.

34. Akhtar, Y.; Yeoung, Y. R.; Isman, M. B.; Phytochem. Rev. 2008, 7, 77.

35. Santos-Oliveira, M.; Bueno, O. C.; Marini, T.; Reiss, I. C.; Bueno, F. C.; Sociobiology 2006, 423.

36. Chaudhary, S.; Kanwar, R. K.; Sehgal, A.; Cahill, D. M.; Barrow, C. J.; Sehgal, R.; Kanwar, J. R.; Front. Plant Sci. 2017, 8, 610.

37. Bernardi, M. M.; Dias, S. G.; Barbosa, V. E.; Environ. Toxicol. Pharmacol. 2013, 36, 1276.

38. Murussi, C. R.; Costa, M. D.; Leitemperger, J. W.; Flores-Lopes, F.; Menezes, C. C.; Loebens, L.; Avila, L. A.; Rizzetti, T. M.; Adaime, M. B.; Zanella, R.; Loro, V. L.; Comp. Biochem. Physiol., C: Comp. Pharmacol. 2016, 180, 49. 